\title{
INVESTIGATIONS OF POLYPROPYLENE FOIL CUTTING PROCESS USING FIBER Nb: YAG AND DIODE Nd:YVO4 LASERS
}

\author{
Leon KUKIELKA*, Radosław PATYK ${ }^{*}$, Łukasz BOHDAL", Wojciech NAPADŁEK", Rafał GRYGLICKI ${ }^{* * *}$, Piotr KASPRZAK ${ }^{* * *}$
}

\author{
${ }^{*}$ Faculty of Mechanical Engineering, Koszalin University of Technology, ul. Racławicka 15-17, 75-620 Koszalin, Poland \\ ${ }^{*}$ Faculty of Mechanical Engineering, Military University of Technology, ul. gen. Sylwestra Kaliskiego 2, 01-476 Warsaw, Poland \\ ${ }^{* * *}$ PHU Kontakt Rafał Gryglicki, ul. Kalinowa 31. 75-667 Koszalin, Poland \\ leon.kukielka@tu.koszalin.pl, radoslaw.patyk@tu.koszalin.pl, lukasz.bohdal@tu.koszalin.pl,wnapadlek@wat.edu.pl, \\ rafal.gryglicki@matsim.pl, piotr.kasprzak@twohorses.pl
}

received 16 May 2019, revised 18 June 2019, accepted 24 June 2019

\begin{abstract}
Lasers are widely used in a variety of manufacturing processes including: depaneling, drilling, cutting, repair, trimming, micromachining. Polypropylene foils are intensively investigated as materials with great number of potential applications. Laser cutting is a major operation used in forming these materials and preparing the final workpieces. At the moment, the main challenge when cutting polypropylene is to obtain high quality products characterized by optimum sheared edge condition, minimum surface damage, freedom from burrs, slivers, edge wave, distortion, residual stresses and to obtain minimum width of HAZ zone. The amount of adjusTab. process parameters and the fact that the influence of these parameters on the process is not fully understood makes it difficult to control the cutting process. In practice, the right setup for the lasers is mostly found by trial and error combined with experience. Therefore, the final product frequently has serious defects. The paper presents the possibility of using fiber and diode lasers for forming of workpieces from polypropylene multilayer foil using cutting technology. The effect of selected process parameters and conditions on quality of sheared edge and material degradation is discussed.
\end{abstract}

Key words: Laser, Cutting, Polypropylene Foil, HAZ

\section{INTRODUCTION}

Polypropylene (PP) has been widely used in many industrial branches. This material is characterized by highly adaptable properties, chemical resistance, thermal stability and physiological compatibility. Cutting is a major operation used in forming these materials and preparing final workpieces (Huang et al., 2012; Bohdal, 2016). It has been found that in comparison with mechanical cutting, for example, blanking or guillotining lasers cause less stresses in the material and reduce the cut surface defects, for example, burrs and edge waves. Our preliminary research showed that burr is the main problem in foils' mechanical cutting, which not only affects the geometrical precision of blanked shapes, it also decreases their assembly.

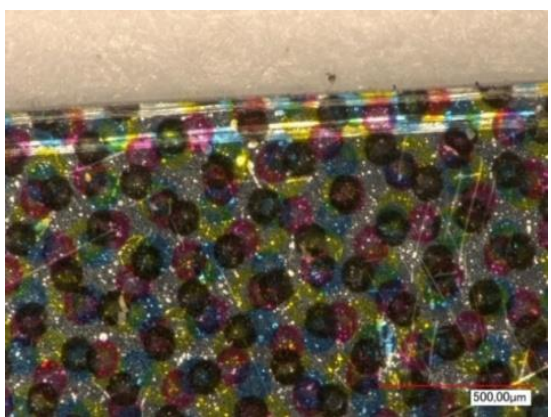

Fig. 1. Rollover formation on cut surface

From technological point of view, it's very problematic to con- trol punch die clearance during blanking or horizontal clearance during shear-slitting operations. The clearance should be minimal and no more than $10 \%$ of the thickness of material being cut (Bohdal, 2016). Larger clearance increases the burr height at cut surface. This requires the use of tools with very high dimensional accuracy. Cutting foils increases the possibility of tools' wear (Arroyoa et al., 2010; Langer et al., 2012; Ragusich et al., 2013; Deng et al., 2013). Tool wear causes the rollover formation (Fig. 1) and burr (Fig. 2). While using laser cutting, because of the contact-free material processing, there is no distortion even when thin materials are used. However, laser cutting results in localized melting or chemical degradation, which is a result of hot ablation (Perry et al., 2009; Wan et al., 2009).

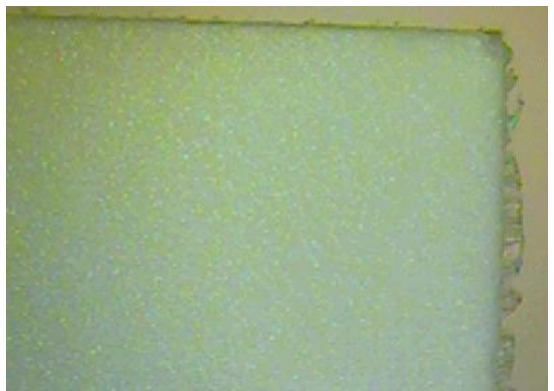

Fig. 2. Burr formation on cut surface

Examples of research, experimental results and numerical models of laser cutting processes can be found in the literature. Karnakis et al. (2010) presented the experimental results of micro- 
machining of polymers and silicon nitride using reshaped pulsed Gaussian laser beam. Sotnikov et al. (2010) analysed the effect of elliptical beam shapes on cutting performance of silicon using a diode pumped solid state Q-switched UV laser operating at the wavelength of $355 \mathrm{~nm}$. Zhang and Faghri (1999) developed a theoretical model to predict the cavity formation for UV laser micro-machining with nanosecond pulse duration. Wang et al. (2008) used UV laser with $355 \mathrm{~nm}$ wave-length to cut the printed circuit boards. Miraouri et al. (2014) analysed high-power $\mathrm{CO}_{2}$ laser cutting of steel plates. The effect of the input laser cutting parameters on the cut surface quality was analysed. An overall optimization was applied to find out the optimal cutting setting that improve the cut surface quality. It was found that laser beam diameter has a negligible effect on surface roughness, but laser power had a major effect on surface roughness. The cut surface roughness decreases as laser power increases. Caiazzo et al. (2005) examined the application of the $\mathrm{CO}_{2}$ laser cutting process to three thermoplastic polymers - polyethylene, polypropylene, polycarbonate - in different thickness ranging from $t=2$ to $10 \mathrm{~mm}$. The analysis of process parameters such as laser power, cutting speed, type of focusing lens, pressure and flow of the covering gas and material thickness on overall process efficiency and quality of cut surface was investigated. The main aim of work developed by Eltawahni et al. (2010) was to relate the cutting edge quality parameters (responses) namely: upper kerf, lower kerf, ratio of the upper kerf to lower kerf and cut edge roughness to the process parameters considered in this research and to find out the optimal cutting conditions of polyethylene. The process factors implemented in this research were: laser power, cutting speed and focal point position. Mathematical models were developed to establish the relationship between the process parameters and the edge quality parameters. Also, the effects of process parameters on each response were determined. A numerical optimization was performed to find out the optimal process setting at which the quality features are at their desired values. A three dimensional model of laser cutting process of some plastics has been presented by Atanasov and Baeva (1997). With this model, it is possible to determine the maximum cutting speed as a function of substrate thickness or laser power. Work presented by Abrao et al. (2007) evaluated the effect of the processing parameters on the quality of the cut for several engineering plastics. It was evident that the heat-affected zone (HAZ) increases with the increase in laser power, but it decreases with increase in the cutting speed. Uebel and Bliedtner (2014) present different cutting methods and types of laser, which were used in the examinations in order to achieve a distortion-low and high-quality cutting of the materials in the sintered and unsintered state at high process velocities. The test results were analysed using picosecond lasers at different wavelengths (1064 nm, $532 \mathrm{~nm}$ and $355 \mathrm{~nm})$. The tests with the sintered materials showed that process quality increases with shorter pulse duration. Additionally, the results can be improved with shorter wavelengths.

There are, however, challenges in laser processing of polypropylene foils, where the goal is to minimise HAZ zone and to use high processing speed. The main problem in practical industry is the amount of adjusTab. laser cutting parameters and the fact that the influence of these parameters on the process is not fully understood. It makes difficult to control the process. In practice, the right setup for the laser parameters is mostly found by trial and error combined with experience. Therefore, the final product frequently has serious defects, for example, sharp edges, rough surfaces along the edges and wide heat affected zone. Among defects, delamination of polypropylene layers appears to be the most critical one (Kurt et al., 2009; Li et al., 2010).

The current work analyses the possibility of using fiber and diode lasers to forming workpieces from multilayer polypropylene foil using cutting technology. The effect of selected process parameters and conditions (for example, shape of cutting line) on quality of sheared edge and material degradation is discussed. The results could be used for proper selection of process conditions.

\section{EXPERIMENTAL SETUP}

The experimental setup is shown in Figs. 3 and 4. The research is realized using fiber laser $\mathrm{Nb}: Y A G$ with wave length $\lambda=1070 \mathrm{~nm}$, frequency $\mathrm{f}=25 \mathrm{kHz}$, constant maximum averaged output power $\mathrm{P}=30 \mathrm{~W}$ and laser $\mathrm{Nd} \mathrm{YVO}_{4}$ with power $\mathrm{P}=5 \mathrm{~W}$, wave length $\lambda=532 \mathrm{~nm}$ and frequency repetition $3 \div 50 \mathrm{kHz}$. A single nanosecond pulse of lasers - carry out about $100 \mathrm{~ns}$. Lasers are integrated with a modern Galvo optical head equipped with a $163 \mathrm{~mm}$ lens, head working field min. $100 \times 100 \mathrm{~mm}$. The lasers spot size is not more than $60 \mu \mathrm{m}$; the base, control automatics, modern software, the column being the ' $z$ ' axis is adapted to fix the Galvo head with precise electric control for its movement.

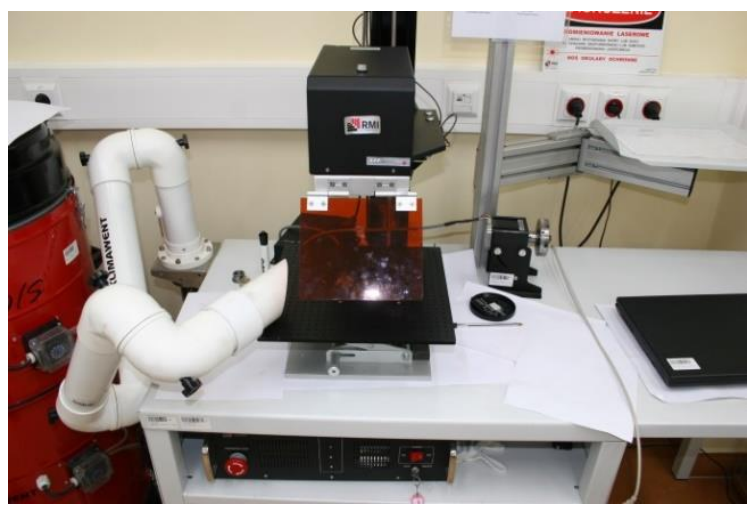

Fig. 3. Experimental setup: fiber $\mathrm{Nb}: Y A G$ laser

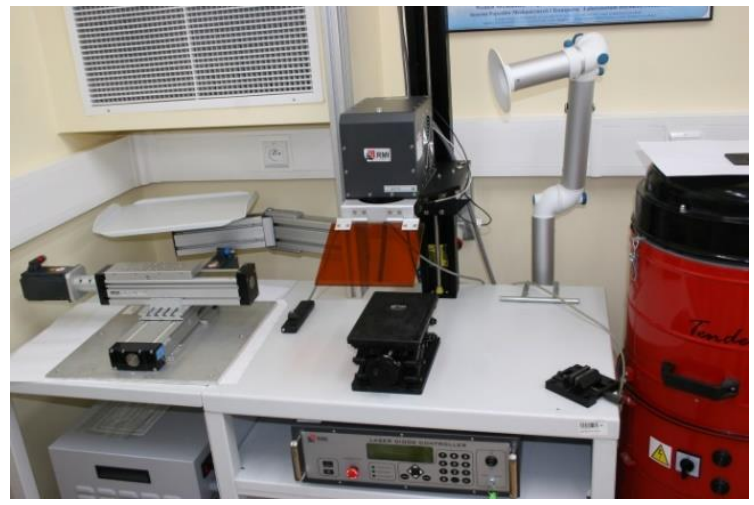

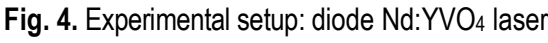

Polypropylene foils with a thickness of $t=80 \mu \mathrm{m}$ are used for the tests. Longitudinal and transverse tensile strength tests of the foils are made in accordance with ASTM D882 norm. 
According to the standard, five samples with a width of 50 $[\mathrm{mm}] \pm 0.5[\mathrm{~mm}]$ are made for each of the tests. Example of samples for testing tensile strength are shown in Fig. 5.

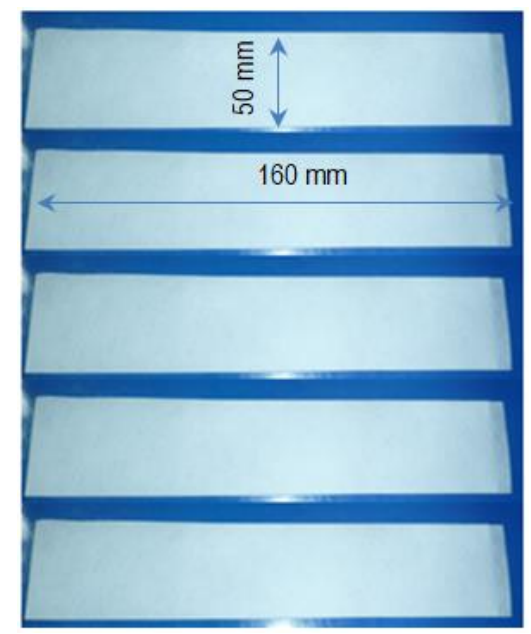

Fig. 5. Example of samples for determination of tensile strength tests

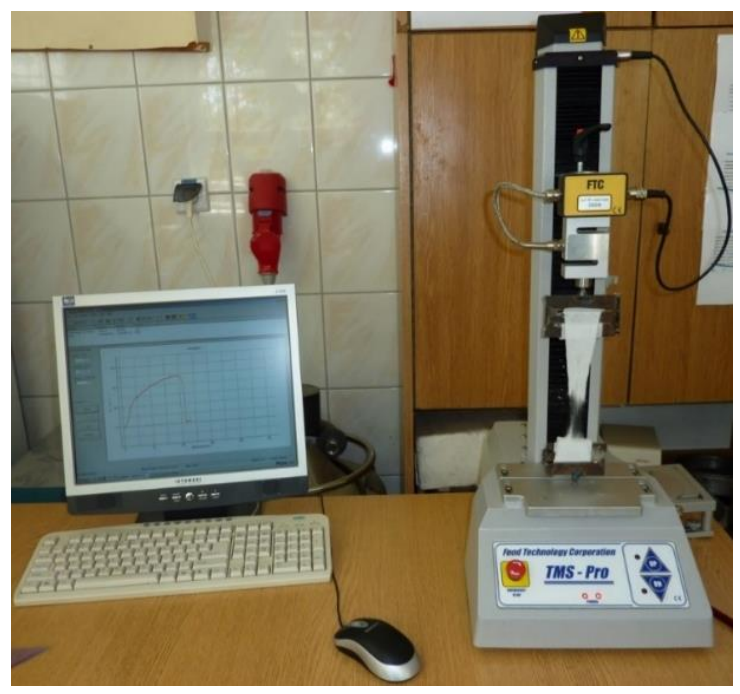

Fig. 6. Photograph of the test stand for force and displacement measurement: Mecmesin TMS PRO with the FTC force sensor, measuring range $0 \div 2500[\mathrm{~N}]$ with an accuracy of $0.1[\mathrm{~N}]$

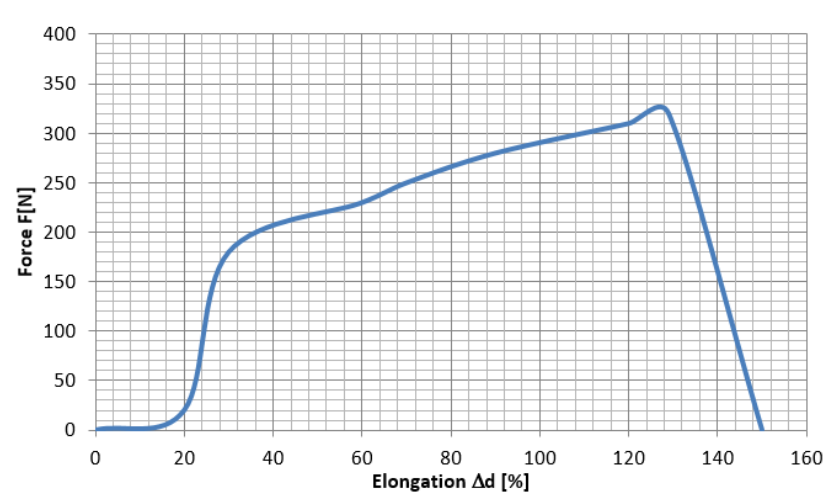

Fig. 7. Graph of changes of tensile force as a function of elongation for the analysed material $(t=80[\mu \mathrm{m}])$

Strength tests are carried out on Mecmesin TMS PRO with a FTC force sensor with a measuring range of $0 \div 2500[\mathrm{~N}]$ with an accuracy of $0.1[\mathrm{~N}]$ test stand. The view of the equipment for strength tests is shown in Fig. 6. The stretching process of the samples is carried out with the jaws' moving speed $v=100$ [mm/min]. Figs. 7 and 8 show the results of longitudinal elongation of testing material. The tested longitudinal tensile strength carry out $\sigma=80(\mathrm{MPa})$. The tested transverse tensile strength carry out $\sigma=149(\mathrm{MPa})$. The material elongation tested is $129 \%$ and the lateral elongation of the material is $44 \%$. These values are important in the production process when the foil tension occurs during its development from the role. The obtained values are sufficient so that production defects resulting from excessive stretching of the film or its tearing during development from the role are not created.

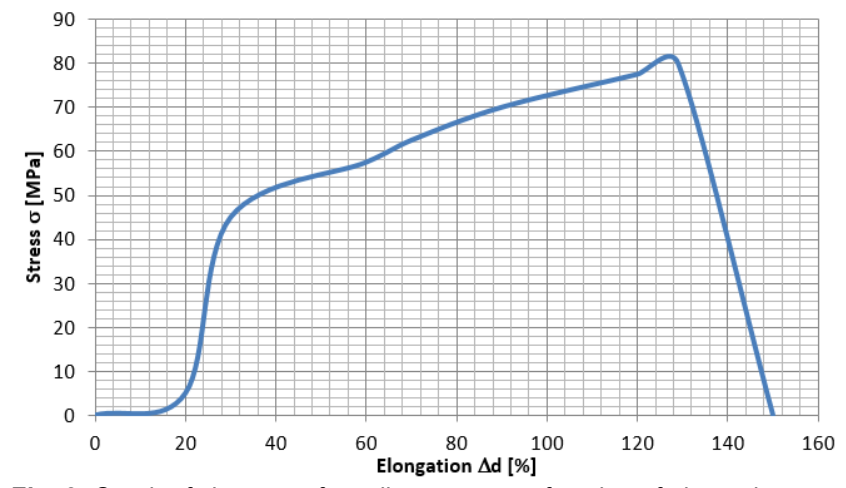

Fig. 8. Graph of changes of tensile stress as a function of elongation for analysed material $(t=80[\mu \mathrm{m}])$

\section{EXPERIMENTAL RESULTS}

At the first case, the research is realized using the fiber laser $\mathrm{Nb}$ :YAG with wave length $\lambda=1070 \mathrm{~nm}$, frequency $\mathrm{f}=25 \mathrm{kHz}$ and constant maximum averaged output power $P=30 \mathrm{~W}$. Foils with a thickness of $t=80 \mu \mathrm{m}$ are used for the tests. Tests are carried out for five replications for each foil. Example of results are given in Fig. 9. For technological reasons, the tests are carried out for constant parameters of cutting speed $v=3 \mathrm{~mm} / \mathrm{s}$ and averaged output power $\mathrm{P}=30 \mathrm{~W}$. It was not possible to achieve complete separation of the material for multilayer foil. Only the melting and charring of the polypropylene foil in the beam's impact zone is found (Fig. 9a and b). The cutting gap is more regular when cutting along the sheet of film. The change in the direction of the cutting caused the increase of local melts for second foil (Fig. 9b). The gap has narrowed. The depth of gap and width of the HAZ zone increased at this region. The average value of the gap width for foil carry out was $S=120 \mu \mathrm{m}$. Developed analysis shows that this type of laser and cutting conditions can be used to cut singlelayer foils and realization of other technological processes, for example, drilling contours, incision or micromachining.

At the second case, the research is realized using the diode $\mathrm{Nd}: \mathrm{YVO}_{4}$ laser. Foils with a thickness of $\mathrm{g}=80 \mu \mathrm{m}$ are used for the tests. Analysis is carried out for output power $\mathrm{P}=5 \mathrm{~W}$ different frequency repetition values ( $f=3 \div 50 \mathrm{kHz}$ ) and changed cutting velocities ( $v=1 \div 3 \mathrm{~mm} / \mathrm{s}$ ). The research is planned using the $\mathrm{E}$ Planner program. Experiment design matrix is given in Tab. 1. From technological point of view it's important to minimalize gap width because it result in material loss (Leone et al., 2013; Kiselev et al., 2011). As a result of hot ablation, HAZ zone is created, which should be minimal at workpiece to reduce chemical degradation of material (Cuong et al., 2010; Zhang et al., 2010). Tests are carried out for five replications for each plan level. The micro- 


\section{S sciendo}

Leon Kukiełka, Radosław Patyk, Łukasz Bohdal, Wojciech Napadkek, Rafał Gryglicki, Piotr Kasprzak Investigations of Polypropylene Foil Cutting Process Using Fiber Nb:Yag and Diode Nd:YVO4 Lasers

scope images of samples after cutting are given in Figs. 10 and 11. The influence of analysed parameters on gap width and $H A Z$ zone width along the shearing line is presented in Figs. 12 and 13.
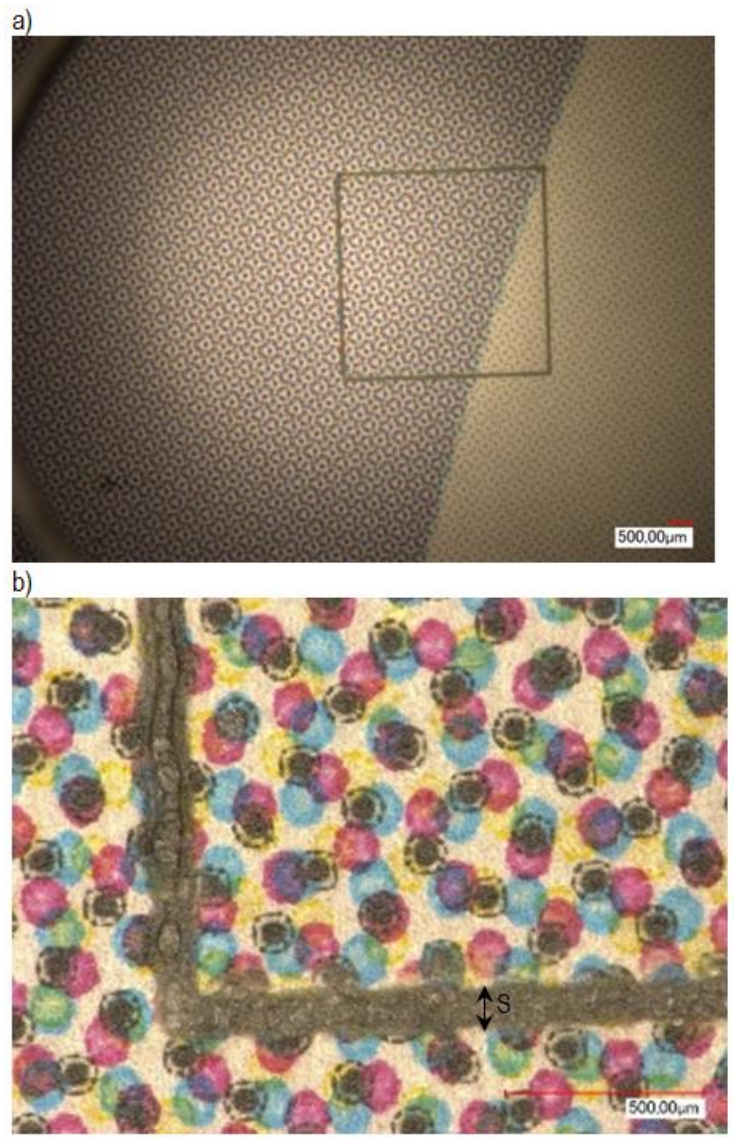

Fig. 9. Example of results obtained using fiber $\mathrm{Nb}$ : YAG laser: a) contour of cutting line (Ax100), b) zoom of the cutting line (Ax200)

Tab 1. Five levels compositive rotary plan

\begin{tabular}{|c|c|c|c|c|}
\hline \multirow{2}{*}{ Plan level } & \multicolumn{3}{|c|}{ Coded variables } & \multicolumn{2}{l|}{ Real variables } \\
\cline { 2 - 5 } & $\breve{\bar{x}}_{1}$ & $\breve{\bar{x}}_{2}$ & $\mathrm{v}$ & $\mathrm{f}$ \\
\cline { 2 - 5 } & & & $(\mathrm{mm} / \mathrm{s})$ & $(\mathrm{kHz})$ \\
\hline 1 & - & - & 1.29 & 9.88 \\
\hline 2 & + & - & 2.70 & 9.88 \\
\hline 3 & - & + & 1.29 & 43.11 \\
\hline 4 & + & + & 2.70 & 43.11 \\
\hline 5 & $+a$ & 0 & 3 & 26.5 \\
\hline 6 & $-a$ & 0 & 1 & 26.5 \\
\hline 7 & 0 & $+a$ & 2 & 50 \\
\hline 8 & 0 & $-a$ & 2 & 3 \\
\hline 9 & 0 & 0 & 2 & 26.5 \\
\hline 10 & 0 & 0 & 2 & 26.5 \\
\hline 11 & 0 & 0 & 2 & 26.5 \\
\hline 12 & 0 & 0 & 2 & 26.5 \\
\hline 13 & 0 & 0 & 2 & 26.5 \\
\hline
\end{tabular}

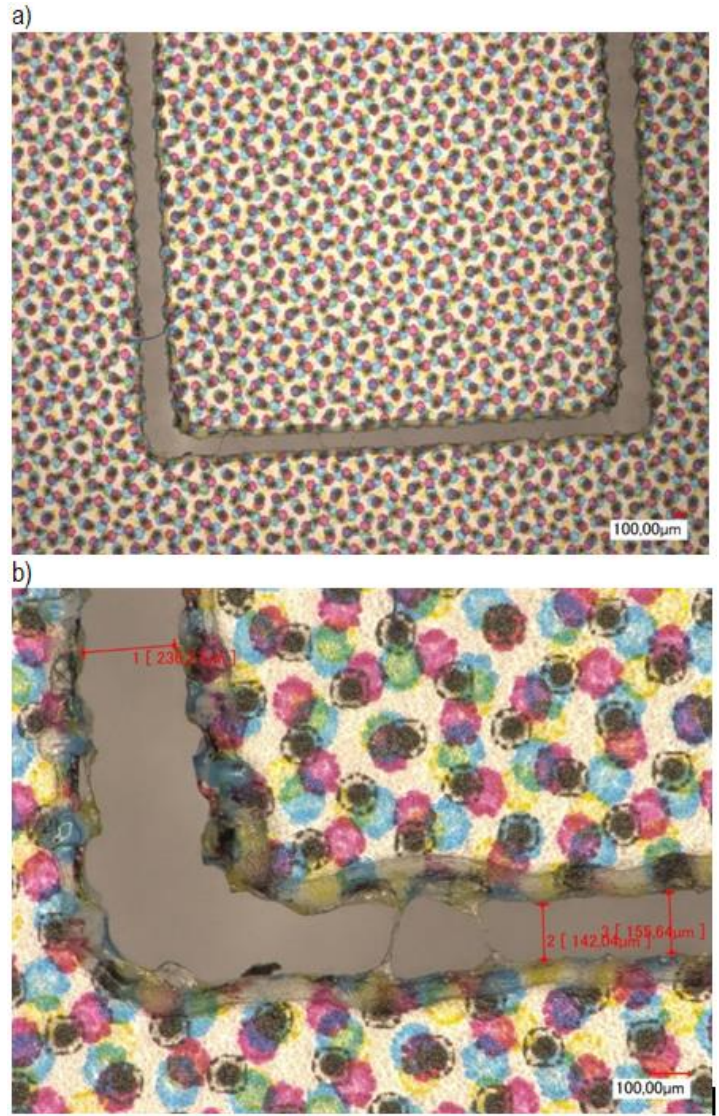

Fig. 10. Example of results obtained using diode $\mathrm{Nd} \mathrm{YVO}_{4}$ laser: $\mathrm{v}=1 \mathrm{~mm} / \mathrm{s}, \mathrm{f}=26.5(\mathrm{kHz})$

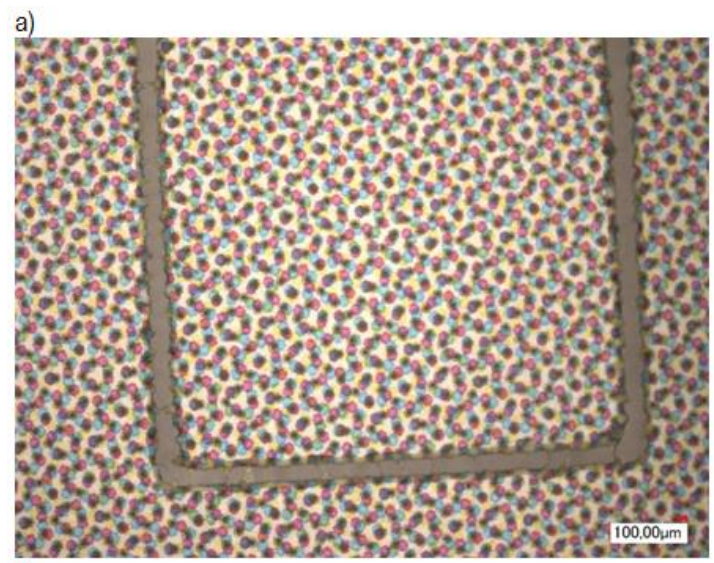

b)

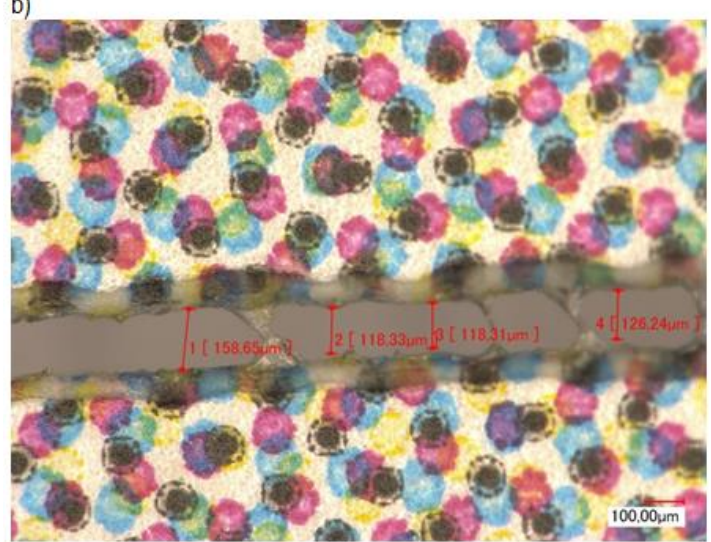

Fig. 11. Example of results obtained using diode $\mathrm{Nd} \mathrm{YVO}_{4}$ laser: $\mathrm{v}=3 \mathrm{~mm} / \mathrm{s}, \mathrm{f}=26,5(\mathrm{kHz})$ 
A mathematical model in the form of a linear algebraic polynomial with interactions is used to describe the object of the research. For gap width, the regression formula is as follows $(R=$ 0.99):

$$
\begin{aligned}
& S=696.605-525.407 \cdot \mathrm{v}-10.796 \cdot \mathrm{f}+0.021 \cdot \mathrm{v} \cdot \mathrm{f}+ \\
& 130.250 \cdot \mathrm{v}^{2}+0.209 \cdot \mathrm{f}^{2},
\end{aligned}
$$

For $\mathrm{HAZ}$ width, the regression formula is as follows ( $R=0.87$ ):

$$
H z=557.128-610.332 \cdot \mathrm{v}-18.754 \cdot \mathrm{f}+0.106 \cdot \mathrm{v} \cdot \mathrm{f}
$$$$
+308.952 \cdot \mathrm{v}^{2}+0.711 \cdot \mathrm{f}^{2}-50.291 \cdot \mathrm{v}^{3}-0.008 \cdot \mathrm{f}^{3},(2)
$$

Fig. 12 shows the effects of the analysed process technological parameters on gap width. The value of gap width depends both on frequency and cutting speed. The minimum gap width was found using parameters from range of: $v=1.6 \div 2.4 \mathrm{~mm} / \mathrm{s}$ and $f=15 \div 35 \mathrm{kHz}$. Selecting values of parameters from outside of this range increases gap width.

It has been observed that the small values of frequency increases the width of HAZ (Fig. 13). The minimum of HAZ can be obtained using middle range of frequencies or high values ( $\mathrm{f}>40 \mathrm{kHz}$ ).

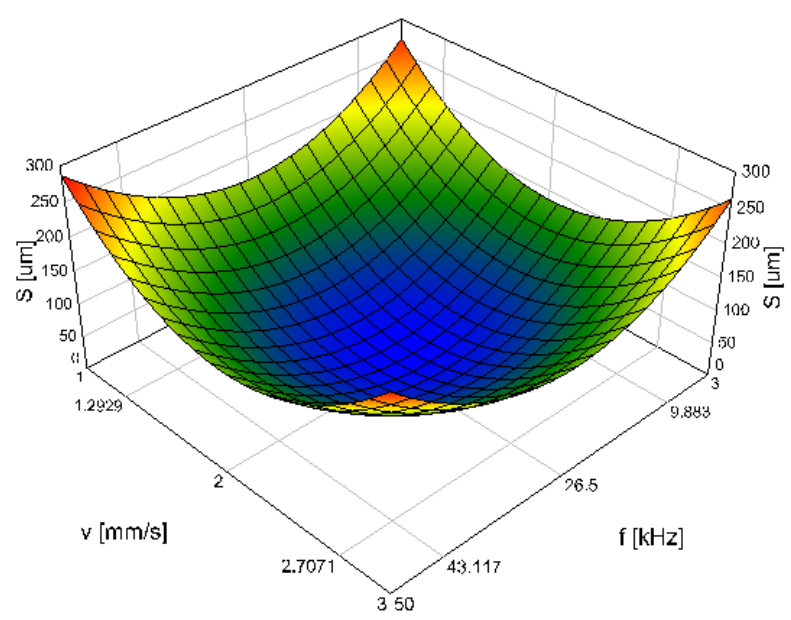

Fig. 12. The influence of frequency $f$ and cutting speed $v$ on gap width $S$

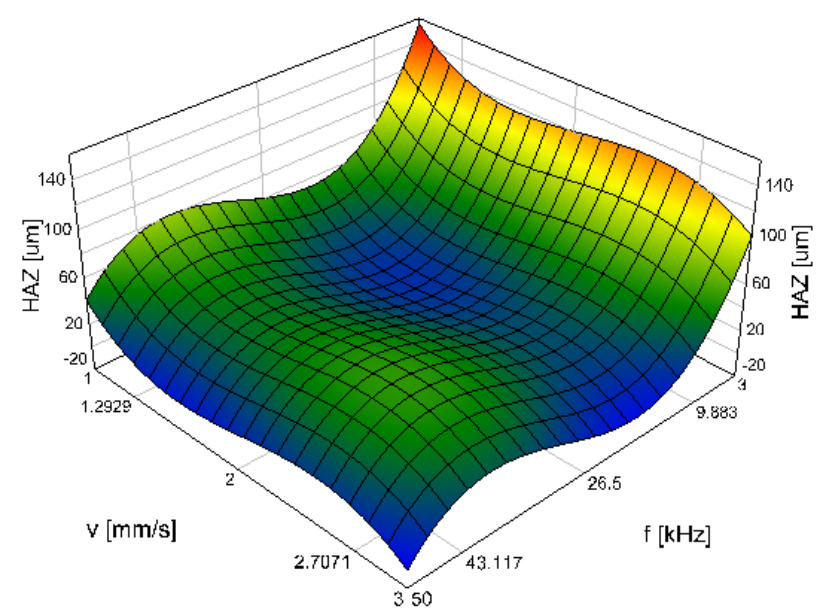

Fig. 13. The influence of frequency $f$ and cutting speed $v$ on $H A Z$ width

Area of acceptable solution is graphically presented in Fig. 14. According to technological criteria $\mathrm{S} \leq 50 \mu \mathrm{m}$ and $\mathrm{HAZ} \mathrm{H}_{\mathrm{z}} \leq 40$ $\mu \mathrm{m}$. The chart can be used for selection of optimal process pa- rameters in the aspect of maximizing process efficiency and minimizing energy consumption with obtaining high quality of workpieces. It is possible to control the cutting process and minimize the material sheared edge defects.

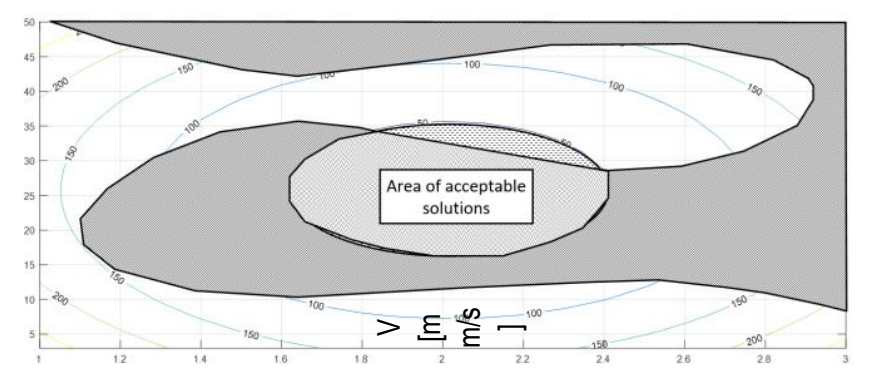

Fig. 14. Chart with area of accepTab. solutions

\section{CONCLUSIONS}

The paper presents the possibility of using fiber and diode lasers to forming workpieces from polypropylene multilayer foil using cutting technology. The results showed the possibility of using fiber laser in the analysed configuration to cut a single layer foil. It can also be used for other technological processes, for example, incision, drilling or micromachining. Using diode laser, it is possible to obtain high quality of workpieces. Analysed two main process parameters' frequency and cutting speed has significant influence on the final workpiece quality. Proper selection of these parameters is a key factor, which determines the HAZ zone and gap width. Obtained results of cutting multilayer polypropylene foil using diode Nd:YVO4 laser can be used for the selection of optimal process parameters in the aspect of maximizing process efficiency and minimizing energy consumption.

\section{REFERENCES}

1. Abrao AM., Faria PE., Campos Rubio JC., Reis P., Paulo Davim J., (2007), Drilling of fiber reinforced plastics: a review. International Journal of Manufacturing Technology, 186: 1-7.

2. Arroyoa J.M, Diniz A.E., Fernandes de Lima M.S., (2010), Wear performance of laser precoating treated cemented carbide milling tools, Wear 268, 1329-1336.

3. Atanasov P. A., Baeva M. G., (1997), CW CO 2 laser cutting of plastics, Proceedings SPIE 3092, 772-775.

4. Bohdal L., (2016), The application of the smoothed particle hydrodynamics (SPH) method to the simulation and analysis of blanking process, Mechanika, 22 (5), 380-387.

5. Caiazzo F., Ciurcio F., Daurelio G., Memola Capece Minutolo F., (2005), Laser cutting of different polymeric plastics (PE, PP and PC) by $\mathrm{CO}_{2}$ laser beam, Journal of Materials Processing Technology, 159, 279-285.

6. Cuong T.V., Pham V.H., Tran Q.T., Hahn S.H., Chung J.S., Shin E.W., Kim E.J., (2010), Photoluminescence and Raman studies of graphene thin films prepared by reduction of graphene oxide, Materials Letters 64, 399-40.

7. Deng J., Li S., Xing Y., Li Y., (2014), Studies on thermal shock resistance of TiN and TiAIN coatings under pulsed laser irradiation, Surface Engineering 30 (3), 195-203.

8. Eltawahni H. A., Olabi A. G., Benyounis K. Y., (2010), Effect of process parameters and optimization of $\mathrm{CO}_{2}$ laser cutting of ultra high performance polyethylene, Materials and Design 31 (8), 40294038. 
9. Huang Y.J., Huang Y.P., Chiang P.Y., Liang H.C., Su K.W., Chen Y.-F. (2012), High-power passively Q-switched Nd:YVO4 UV laser at $355 \mathrm{~nm}$, Applied Physics B., 106, 893-898.

10. Karnakis D., Fieret J., Rumsby P., Gower M. (2010), Microhole drilling using reshaped pulsed Gaussian beams (private correspondence).

11. Kiselev A. M., Ponomarev Yu. N., Stepanov A. N., Tikhomirov A. B., Tikhomirov B. A., (2011), Nonlinear absorption of femtosecond laser pulses $(800 \mathrm{~nm})$ by atmospheric air and water vapour, Quantum Electronics 41 (11), 976-980.

12. Kurt M., Kaynak Y., Bagei E., Demirer H., Kurt M., (2009), Dimensional analyses and surface quality of laser cutting process for engineering plastics, International Journal of Manufacturing Technology, 41, 259-267.

13. Langer M., Rechner R., Thieme M., Jansen I., Beyer E., (2012), Surface analytical characterisation of Nd:YAG-laser pre-treated Al Mg3 as a preparation for bonding, Solid State Sciences 14(7):92635 .

14. Leone C., Papa I., Tagliaferri F., Lopresto V., (2013), Investigation of CFRP laser milling using a 30W Q-switched Yb:YAG fiber laser: Effect of process parameters on removal mechanisms and HAZ formation. Composites Part A: Applied Science and Manufacturing $55,129-42$.

15. Li Z.L., Zheng H.Y., Lim G.C., Chu P.L., Li L., (2010), Study on UV laser machining quality of carbon fiber reinforced composites. Composites: Part A 41, 1403-1408.

16. Miraouri I., Boujelbene M., Bayraktar E. (2014), Analysis of roughness and heat affected zone of steel plates obtained by laser cutting, Advanced Materials Research, 974,169-173.

17. Perry T.L., Werschmoeller D., Li X.C., Pfefferkorn F.E., Duffie N.A., (2009), Pulsed laser polishing of micro-milled Ti6Al4V samples. Journal of Manufacturing Processes 11(2):74-81.

18. Ragusich A., Taillon G., Meunier M., Martinu L., KlembergSapieha J.E., (2013), Selective pulsed laser stripping of TiAIN erosion-resistant coatings: effect of wavelength and pulse duration, Surface Coating Technology 232, 758-766.
19. Sotnikov A., Laux H., Stritzker B., (2010), Experimental and Numerical Optimization of Beam Shapes for Short-Pulse Ultraviolet Laser Cutting Processing, Physics Procedia 5, 137-146.

20. Uebel M., Bliedtner J., (2014), Laser precision cutting of highmelting metal foils, Procedia Engineering 69, 99-103.

21. Wan D.P., Liang X.C., Meng F.M., Hu D.J., Wang Y.M., Chen N.K, Shao T.M., (2009), Automatic compensation of laser beam focusing parameters for flying optics. Optics and Laser Technology 41(4):499-503.

22. Wang X.C., Li Z.L., Chen T., Lok B.K., Low D.K.Y. (2008), 355nm DPSS UV laser cutting of FR4 and BT/epoxy-based PCB substrates, Opt. Lasers Eng. 46, 404-409.

23. Zhang Y., Faghri A., (1999) Int. J. Heat Mass Transfer 42, 1775.

24. Zhang Y.-L., Guo L., Wei S., He Y., Xia H., Chen Q., Sun H.-B., Xiao F.-S., (2010), Direct imprinting of microcircuits on graphene oxides film by femtosecond laser reduction, Nano Today 5, 15-20.

Acknowledgements: This work was financially supported by the National Centre for Research and Development Operational Programme Intelligent Development no. agreement POIR.01.01.01-00-0933/17-00.

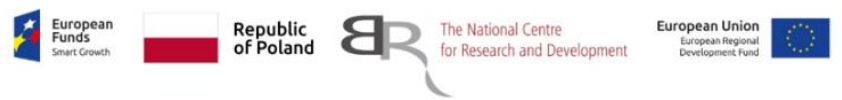

